\title{
Fasting serum lipids and fundus changes in hypertensive patients
}

\author{
Bastola $\boldsymbol{P}^{1^{*}}$ Pun $\mathrm{CB},{ }^{2}$ Koirala $S,{ }^{3}$ Shrestha $\mathrm{UK}^{4}$ \\ ${ }^{1}$ Nepalgunj Eye Hospital, Nepalgunj, Nepal, ${ }^{2}$ Department of Medicine, Gandaki Medical College and Teaching Hospital, \\ Kaski, Pokhara, Nepal, ${ }^{3}$ National Academy of Medical Sciences (NAMS), Kathmandu, Nepal, ${ }^{4}$ Department of Medicine, \\ Manipal College of Medical Sciences, Pokhara, Nepal
}

\author{
*Corresponding Author: \\ Dr. Pradeep Bastola, MD, \\ Nepalgunj Eye Hospital, Nepalgunj, Nepal \\ Email: pbs_dinku@yahoo.com; \\ drbastola15@gmail.com
}

\section{Citation}

Bastola P, Pun CB, Koirala S, Shrestha UK. Fasting serum lipids and fundus changes in hypertensive patients. Nepal Journal of Medical sciences 2012;1(2):103-7.

\begin{abstract}
Background: To evaluate fasting serum lipid profile and fundus changes in hypertensive patients,and grade the hypertensive status.

Methods: One hundred consecutive subjects of hypertension, fitting inclusion criteria, with or without prior history of antihypertensive treatment were enrolled in a cross-sectional, descriptive study. Classification of hypertension was done based on The Seventh Report of the Joint National Committee (JNC 7). All the subjects (200 eyes) were subjected to a detailed fundus examination Fundus changes were classified according to Keith, Wagener and Barker (KWB), and Modified Scheie's grading system. Fasting serum lipids were measured using end point spectrophotometer. Data were collected using a prestructured proforma and analyzed using SPSS 19.0.

Results: The mean age of participants was 58.5 years ( $\mathrm{SD}=9.2$ years; range $=33-84$ years $)$.One patient, according to the JNC 7 classification of hypertension was in stage 1 while 99 patients were in stage 2 . Twenty eight subjects had electrocardiographic a b n ormality needing prompt treatment. According to KWB classification 54 patients had hypertensive retinopathy (HR), while by Scheie's grading, 50 patients had HR. Statistically significant difference was found in mean cholesterol, LDL and triglyceride level was seen in different grades of HR.

Conclusion: Significant number of hypertensive patients had HR on first presentation to department of Ophthalmology. Mean serum cholesterol, LDL and triglyceride levels were raised in patients with HR.
\end{abstract}

Keywords: Hypertensive retinopathy; serum lipids; serum cholesterol; triglycerides

\section{Background:}

Systemic hypertension is a state of persistently elevated blood pressure above 140/90 $\mathrm{mm}$ of $\mathrm{Hg}$ based on an average of two or more bloodpressure readings taken on two or more visits. ${ }^{1}$ Hypertension is the most common primary diagnosis in America (35 million office visits as the primary

diagnosis). ${ }^{2}$ Hypertension affects approximately 50 million individuals in the United States and approximately one billion worldwide. However, in developing countries like Nepal, the prevalence of hypertension may not be as high as in the developed countries, but exact data from population based studies is sparse. 
As the population ages, the prevalence of hypertension will increase even further unless broad and effective preventive measures are implemented. Recent data from the Framingham Heart Study suggest that individuals who are normotensive at age 55 have a 90 percent life time risk for developing hypertension. ${ }^{2}$

A spectrum of vascular changes can be seen in retinal vasculature of patients with hypertension and these changes are called as hypertensive retinopathy (HR). The seventh report of the Joint National Committee (JNC 7) on prevention, detection, evaluation and treatment of high blood pressure recommends evaluation of $\mathrm{HR}$ as a part of standard care of hypertension and lists HR as a marker of target organ damage. Presence of HR alone in people with stage 1 hypertension may be an indication of starting antihypertensive treatment. Some of the signs of HR (e.g. retinal haemorrhage, cotton wool spot and microaneurysms) predict stroke and stroke related death indepently of hypertension and other risk factors. Prolonged uncontrolled systemic hypertension may result in visual impairment or blindness. It is known that hypertension aggravates atherosclerosis and vice versa.

The pathophysiology of HR is not yet well understood however dyslipidemia may play a contributory role. One study from Nepal has shown increased level of LDL in HR; however other parameters of lipid profile were not assessed. ${ }^{3}$ In this study we aimed to find the prevalence of HR in Nepalese population as well as to study the relationship between HR and abnormalities of fasting lipid profile.

\section{Methods:}

This was a hospital based, cross-sectional, descriptive study, where intervention was done as per requirement. This study was carried out in Gandaki Medical College and Teaching Hospital, Kaski, Pokhara, Nepal from October 2010 to end of November 2010. Approval from the Ethical approval committee was taken prior to the study and a standard proforma was made for data entry.

One hundred subjects of systemic hypertension were included in the study, which were diagnosed as hypertensive either in the department of Medicine or elsewhere previously. None of the subjects had undergone detailed ocular examination for fundus changes prior to presenting to Ophthalmology out-patient department. All the subjects were investigated for fasting serum lipid profile. Measurement of serum fasting lipids was done by end point method using spectrophotometer. Other investigations like electrocardiography, blood urea, serum creatinine, fasting blood sugar and postprandial blood sugar were also done. Patients with diabetes were excluded from the study.

The stage of hypertension was classified according to JNC 7 criteria. $^{2}$ Hypertensive fundus changes and atherosclerotic and hypertensive fundus changes were evaluated usingthe Keith - Wagener and Barker (KWB $)^{4}$ and Scheie's (all types) Classification. ${ }^{5}$ Two systems for hypertensive changes were used to detect the changes correctly, as number of times, with KWB classification group 1 and group 2, changes of retinopathy can be very doubtful and same applies for group 1 hypertensive changes and normal fundus.

All subjects underwent a detailed ocular examination including mydriasis. Direct Ophthalmoscopy and indirect Ophthalmoscopy was done using direct Ophthalmoscope and 78 dioptre lens and, 20 dioptre lenses. Positive findings were noted, and entered in a proforma specifically designed for the study, and statistical analysis was done using Statistical Package for Social sciences (SPSS) version 19.0. The various components of fasting serum lipid profile of the patients were compared with changes in fundus using one way Anova test. Post Hoc analysis using Tukey's HSD was performed when one way Anova found statistically significant difference.

\section{Results:}

A total of 100 subjects (62 male and 38 female) diagnosed to have hypertension were included in this study. The mean age of the study group was 58.5 years $(\mathrm{SD}=9.2$ years; range= 33- 84 years). According to JNC 7 criteria one case had stage I hypertension while the rest had stage II hypertension.

The prevalence of HR using KWB and modified Scheie's grading are summarized in table 1 .

\section{Table 1:Prevalence of different grades of hypertensive} retinopathy

\begin{tabular}{lcc}
\hline $\begin{array}{l}\text { Hypertensive } \\
\text { retinopathy }\end{array}$ & KWB & $\begin{array}{c}\text { Modified } \\
\text { Scheie's grade }\end{array}$ \\
\hline Normal fundus & 46 & 50 \\
Grade I & 22 & 20 \\
Grade II & 16 & 17 \\
Grade III & 14 & 11 \\
Grade IV & 2 & 2 \\
\hline
\end{tabular}

There was statistically significant difference in mean Serum Cholesterol level $(\mathrm{F}=10.38 ; \mathrm{p}<0.001)$; mean LDL level $(\mathrm{F}=$ 
30.39; $\mathrm{P}<0.001)$ and mean TG level $(\mathrm{F}=4.80 ; \mathrm{P}<0.001)$ of patients with normal fundus and those with different grades of HR (Table 2, 3, 4). High density lipoprotein and Very high density lipoprotein were not raised.

Table 2: showing significant difference in the mean serum cholesterol levelin different stages of hypertensive retinopathy.

\begin{tabular}{|c|c|c|c|c|c|}
\hline $\begin{array}{l}\text { Fundus changes, } \\
\text { grading by } \\
\text { Keith - } \\
\text { Wagener, and } \\
\text { Barker }\end{array}$ & $\begin{array}{c}\text { Mean } \\
\text { (mgs/dl) }\end{array}$ & $\mathrm{N}$ & $\begin{array}{c}\text { Std. } \\
\text { Deviation }\end{array}$ & F value & $P$ value \\
\hline Normal Fundus & 169.2 & 46 & 33.47 & & \\
\hline $\begin{array}{l}\text { Grade I } \\
\text { hypertensive } \\
\text { retinopathy }\end{array}$ & 188.0 & 22 & 40.74 & & \\
\hline $\begin{array}{l}\text { Grade II } \\
\text { hypertensive } \\
\text { retinopathy }\end{array}$ & 215.4 & 16 & 33.22 & 10.38 & $<0.001$ \\
\hline $\begin{array}{l}\text { Grade III } \\
\text { hypertensive } \\
\text { retinopathy }\end{array}$ & 219.7 & 14 & 32.65 & & \\
\hline $\begin{array}{l}\text { Grade IV } \\
\text { hypertensive } \\
\text { retinopathy }\end{array}$ & 240.0 & 2 & 19.79. & & \\
\hline
\end{tabular}

Table 3: Showing statistically significant difference in Mean LDL levels in different grades of hypertensive retinopathy

\begin{tabular}{lccccc}
\hline $\begin{array}{c}\text { Fundus changes, } \\
\text { grading by } \\
\begin{array}{c}\text { Keith - } \\
\text { Wagener, and } \\
\text { Barker }\end{array}\end{array}$ & $\begin{array}{c}\text { Mean } \\
(\mathrm{mgs} / \mathrm{dl})\end{array}$ & $\mathrm{N}$ & $\begin{array}{c}\text { Std. } \\
\text { Deviation }\end{array}$ & F Value P Value \\
\hline Normal Fundus & 99.6 & 46 & 22.26 & & \\
$\begin{array}{l}\text { Grade I } \\
\text { hypertensive } \\
\text { retinopathy }\end{array}$ & 125.1 & 22 & 32.48 & & \\
$\begin{array}{l}\text { Grade II } \\
\text { hypertensive } \\
\text { retinopathy }\end{array}$ & 151.1 & 16 & 20.40 & 30.39 & $<0.001$ \\
$\begin{array}{l}\text { Grade III } \\
\text { hypertensive } \\
\text { retinopathy }\end{array}$ & 169.3 & 14 & 21.31 & \\
$\begin{array}{l}\text { Grade IV } \\
\text { hypertensive } \\
\text { retinopathy }\end{array}$ & 177.5 & 2 & 30.40 & \\
\hline
\end{tabular}

Table 4: showing statistically significant difference in mean triglycerides level fordifferent level ofHypertensiveretinopathy

\begin{tabular}{|c|c|c|c|c|c|}
\hline $\begin{array}{l}\text { Fundus changes, } \\
\text { gradingby } \\
\text { Keith - Wagener, } \\
\text { and Barker }\end{array}$ & $\begin{array}{c}\text { Mean } \\
(\mathrm{mgs} / \mathrm{dl})\end{array}$ & $\mathrm{N}$ & $\begin{array}{c}\text { Std. } \\
\text { Deviation }\end{array}$ & F Value & P Value \\
\hline Normal Fundus & 150.3 & 46 & 39.57 & & \\
\hline $\begin{array}{l}\text { Grade I } \\
\text { hypertensive } \\
\text { retinopathy }\end{array}$ & 165.0 & 22 & 31.02 & & \\
\hline $\begin{array}{l}\text { Grade II } \\
\text { hypertensive } \\
\text { retinopathy }\end{array}$ & 169.7 & 16 & 58.50 & 4.80 & $<0.001$ \\
\hline $\begin{array}{l}\text { Grade III } \\
\text { hypertensive } \\
\text { retinopathy }\end{array}$ & 200.8 & 14 & 50.33 & & \\
\hline $\begin{array}{l}\text { Grade IV } \\
\text { hypertensive } \\
\text { retinopathy }\end{array}$ & 225.0 & 2 & 7.07 & & \\
\hline
\end{tabular}

Post hoc analysis using Tukey's HSD showed that there was statistically significant difference in mean serum cholesterol of patients with normal fundus and those with grade II, III and IV HR (Table 5).

Table 5:showing a significant difference in Serumcholesterol levels between normal fundus grouppatients with Grade II,Grade III and Grade IV, hypertensive retinopathy groups

\begin{tabular}{cccc}
\hline $\begin{array}{c}\text { Fundus changes } \\
\text { (Keith, Wagner, } \\
\text { Barker) }\end{array}$ & $\begin{array}{c}\text { Mean } \\
\text { difference }\end{array}$ & P value & 95\% CI \\
\hline Normal vs grade I & -18.7 & 0.240 & $-43.98 ; 6.41$ \\
Normal vs grade II & $-46.1^{*}$ & $<0.001$ & $-74.39 ;-17.96$ \\
Normal vs grade III & $-50.4^{*}$ & $<0.001$ & $-80.12 ;-20.77$ \\
Normal vs grade IV & $-84.7^{*}$ & 0.010 & $-154.96 ;-14.51$ \\
Grade I vs grade II & -27.3 & 0.128 & $-59.33 ; 4.55$ \\
Grade I vs grade III & -31.6 & 0.070 & $-64.90 ; 1.56$ \\
Grade I vs grade IV & -65.9 & 0.087 & $-137.75 ; 5.84$ \\
Grade II vs grade III & -4.2 & 0.997 & $-39.85 ; 31.30$ \\
Grade II vs grade IV & -38.5 & 0.584 & $-111.47 ; 34.35$ \\
Grade III vs grade IV & -34.2 & 0.693 & $-107.77 ; 39.20$ \\
\hline
\end{tabular}

Similarly statistically significant difference in mean LDL 
levels of patients with normal fundus and grade I HR from patients with grade II, III and IV HR (Table 6).

Table 6: showing significant difference between mean LDL levels in patients with normal fundus group and patients withGrade I retinopathy with rest ofthe groups

\begin{tabular}{lccc}
$\begin{array}{c}\text { Fundus changes } \\
\text { (Keith, Wagner, } \\
\text { Barker) }\end{array}$ & $\begin{array}{c}\text { Mean } \\
\text { difference }\end{array}$ & P value & $95 \%$ CI \\
\hline Normal vs grade I & $-25.5^{*}$ & .001 & $-43.31 ;-7.83$ \\
Normal vs grade II & $-51.5^{*}$ & $<0.001$ & $-71.37 ;-31.65$ \\
Normal vs grade III & $-69.7^{*}$ & $<0.001$ & $-90.63 ;-48.86$ \\
Normal vs grade IV & $-77.8^{*}$ & $<0.001$ & $-127.32 ;-28.46$ \\
Grade I vs grade II & $-25.9^{*}$ & .015 & $-48.42 ;-3.45$ \\
Grade I vs grade III & $-44.1^{*}$ & .000 & $-67.57 ;-20.77$ \\
Grade I vs grade IV & $-52.3^{*}$ & .039 & $-102.86 ;-1.77$ \\
Grade II vs grade III & -18.2 & .262 & $-43.27 ; 6.81$ \\
Grade II vs grade IV & -26.3 & .611 & $-77.70 ; 24.95$ \\
Grade III vs grade IV & -8.1 & .992 & $-59.87 ; 43.58$ \\
\hline
\end{tabular}

The difference in mean TG levels of patients with normal fundus and those with grade II $\mathrm{HR}$ was statistically significant (Table 7).

Table 7: showing significant difference in TG levels between normal fundus groupand Grade III hypertensive retinopathy group, whilerest ofthe groups showed no significant difference

\begin{tabular}{cccc}
$\begin{array}{c}\text { Fundus changes } \\
\text { (Keith, Wagner, } \\
\text { Barker) }\end{array}$ & $\begin{array}{c}\text { Mean } \\
\text { difference }\end{array}$ & P value & $95 \%$ CI \\
\hline Normal vs grade I & -14.6 & 0.681 & $-45.59 ; 16.28$ \\
Normal vs grade II & -19.4 & 0.528 & $-54.04 ; 15.24$ \\
Normal vs grade III & $-50.5 *$ & 0.002 & $-86.94 ;-14.07$ \\
Normal vs grade IV & -74.6 & 0.122 & $-160.86 ; 11.56$ \\
Grade I vs grade II & -4.7 & 0.997 & $-43.96 ; 34.46$ \\
Grade I vs grade III & -35.8 & 0.113 & $-76.66 ; 4.94$ \\
Grade I vs grade IV & -60.0 & 0.328 & $-148.15 ; 28.15$ \\
Grade II vs grade III & -31.1 & 0.283 & $-74.78 ; 12.57$ \\
Grade II vs grade IV & -55.2 & 0.429 & $-144.76 ; 34.26$ \\
Grade III vs grade IV & -24.1 & 0.945 & $-114.36 ; 66.08$ \\
\hline
\end{tabular}

\section{Discussion:}

Systemic hypertension is a chronic multi-factorial disease due to the interaction of various abnormalities in the body system. The brain, heart, eyes and the kidneys are most likely to be affected due to persistent elevation of arterial pressure and increased peripheral resistance. Systemic hypertension affects the arteries, veins, choroid and the optic nerve in the eyes. The retinal vasculature changes may be the reflection of the changes of the vasculature of other organs of the body especially the target organs or can occur concurrently. ${ }^{6}$

The prevalence of HR in this study was $56 \%$ by KWB hypertensive retinopathy classification and $50 \%$ by Scheie's grading system for hypertensive and atherosclerotic changes in the retinal microvasculature. When compared with various studies done in the past like Cardiovascular health study, Beamer Dam Eye study, ${ }^{8}$ Atherosclerosis in Communities study, ${ }^{9}$ Blue Mountains eye study, ${ }^{10,11}$ The prevalence of HR in these study were much less which ranged from $8-15 \%$.

The study population in above mentioned studies were large which ranged from 2056-10358 in numbers, however the study of ours had study population of 100 . The higher prevalence of HR in our study may be due to late presentation of the patients to the hospital, uncontrolled hypertension, patient not taking anti-hypertensive medication regularly, and lack of regular follow up in the hospital, lack of awareness with regard to hypertension in the community and concurrent presence of other chronic illnesses.

Though it is known by now that serum low density lipoprotein levels are raised in coronary artery disease. ${ }^{3}$ There are very few reports on whether serum lipoprotein level is raised significantly in HR. Current study showed that the serum lipids were statistically significantly raised in hypertensive with fundus changes and in mean time, study also focused on difference in significance between the different groups in different stages of hypertensive retinopathy. The findings were similar to another study done in Nepal with a smaller sample size. ${ }^{3}$ Another population based study has shown that, signs of HR are strongly associated with rise in blood pressure, but is not consistently associated with the serum lipid levels and other risk factors for atherosclerosis. ${ }^{12}$ This study however showed that the serum lipids were statistically significantly raised in hypertensive with fundus changes. A similar study done in the past with regard to serum lipids and hypertension concluded that Serum cholesterol and serum lipids were raised while free fatty acids were normal in persons having hypertension without retinopathy in comparison to normal persons. In patients having HR the free fatty acids, serum 
lipids, and serum cholesterol were raised in comparison to normal persons. Further in HR subjects, in comparison to hypertensive subjects without retinopathy, the serum lipids and serum cholesterol were not significantly raised but free fatty acids were significantly raised in HR subjects-higher the grade of hypertensive retinopathy greater was the concentration of serum free fatty acids. ${ }^{13}$ This study when compared to the present study of ours resembled quite a bit.

Signs of HR such as generalized and focal retinal arteriolar narrowing and arteriovenous nicking are weakly associated with systemic vascular diseases. Signs of moderate HR are strongly associated with subclinical cerebrovascular disease and can predict incident clinical stroke, congestive heart failure and cardiovascular mortality, independent of hypertension and other traditional risk factors. ${ }^{12}$

In the current study it was seen that mean serum cholesterol level, mean triglyceride level and mean LDL levels were raised significantly in people with grade II or higher grades of HR. It would be premature to confidently conclude that dyslipidemia plays a significant role in the pathogenesis of HR; however the association between dyslipidemia and HR warrants further studies to ascertain its role in pathogenesis and the impact of treatment of dyslipidemia on HR.

We can however confidently conclude that routine opthalmological check up of hypertensive patients is a must; particularly in view of high prevalence of HR in our setting. In patients having signs of HR further evaluation of cardiovascular risk factors including a lipid profile is also warranted as early identification and treatment of these risk factors may be helpful in preventing blindness as well as cardiovascular morbidity and mortality.

\section{Conclusion:}

HR was present in 54 (according to KWB criteria) and 50 (according to modified Scheie's grades) hypertensive patients. This study showed that the serum lipids in patients with hypertensive fundus changes were found to be raised significantly. In general serum cholesterol, triglyceride and LDL were found to be significantly raised in people with grade II or higher grades of HR.

\section{Acknowledgements:}

I would like to thank Mrs. Sheela Bastola for helping in statistical analysis and maintaining the data through out the study.

\section{Conflict of interest: none}

\section{References:}

1. Joint National Committee of detection, evaluation and treatment of high blood pressure. The fifth report of the joint national committee. Arch Intern Med 1993; 153:154-83.

2. Chobanian AV, Bakris GL, Black HR, et al.The seventh report of the Joint National Committe on Prevention, Detection, Evaluation, and Treatment of High Blood Pressure. Hypertension 2003;42:1206-52.

3. Badhu B, Dulal S, Baral N, et al. Serum levels of low density lipoprotein cholesterol in hypertensive retinopathy. Southeast Asian J Trop Med Public Health 2003;34:199-201.

4. Keith NM, Wagener HP, Baker NW. Some different types of essential hypertension: their cause and prognosis. Am J Med Sci 1939;197:332-43.

5. Scheie HG. Evaluation of Ophthalmoscopic changes of hypertension and arteriolar sclerosis. Arch Ophthalmol 1953;49:117-38.

6. Karki KD. Incidence of Ophthalmoscopic fundus changes in hypertensive patients. Kathmandu Univ Med J 2003;1:27-31.

7. Wong TY, Hubbard LD, Klein R, et al. Retinal microvascular abnormalities and blood pressure in older people: the cardiovascular health study. $\mathrm{Br} \mathrm{J}$ Ophthalmol 2002;86:1007-13.

8. Klein R, Klein BE, Moss SE, et al. Hypertension and retinopathy, arteriolar narrowing, and arteriovenous nicking in a population. Arch Ophthalmol 1994;112:92-8.

9. Wong TY, Klein R, Couper DJ, et al. Retinal microvascular abnormalities and incident stroke: the atherosclerosis risk in communities study. Lancet 2001;358:1134-40.

10. Wang JJ, Mitchell $\mathrm{P}$, Leung H, et al. Hypertensive retinal vessel wall signs in a general older population: the Blue Mountains eye study. Hypertension 2003;42:534-41.

11. Yu T, Mitchell P, Berry G, et al. Retinopathy in older persons without diabetes and its relationship to hypertension. Arch Ophthalmol 1998;116:83-9.

12. Wong TW, McIntosh R. Hypertensive retinopathy signs as risk indicators of cardiovascular morbidity and mortality. Br Med Bull 2005;73:57-70.

13. Singh K, Mehra KS, Gode KG, et al. Serum lipids in hypertensive retinopathy. Indian $\mathrm{J}$ Ophthalmol 1975;23:9-11 